\title{
ANÁLISE DE PERCEPÇÃO QUALITATIVA DO TRANSPORTE PÚBLICO: UM ESTUDO DE CASO NA CIDADE DE BELÉM/PA
}

\section{Qualitative perception analysis of public transport: a case study in Belém / PA}

\author{
Ricardo Bentes Kato ${ }^{1}$, Bernardo Macêdo Bordalo ${ }^{2}$, Tiago da Silva Camelo ${ }^{3}$
}

Recebido em 18 de maio de 2015; recebido para revisão em 25 de maio de 2015; aceito em 18 de janeiro de 2016; disponível on-line em 21 de março de 2016.

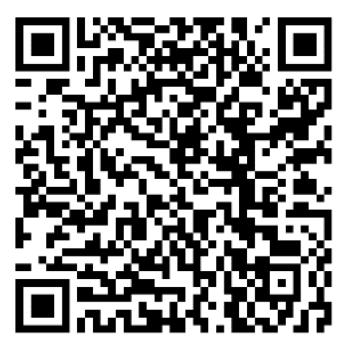

PALAVRAS CHAVE:

Transporte público; Gestão da qualidade; Análise de percepção; Sistema de transporte; Políticas públicas.

\section{KEYWORDS:}

Public transportation; Quality management; Perception Analysis; Transportation system; Urban policy.

* Contato com os autores:

${ }^{1}$ e-mail: r.kato@hotmail.com (R. B. Kato)

Doutorando em Engenharia (UFPA), Mestre em Engenharia Civil (UFSC), Professor da Universidade Federal do Pará.

2e-mail: BMBordalo@hotmail.com (B. M. Bordalo )

Acadêmico do curso de Engenharia Civil da Universidade Federal do Pará.

3 e-mail: tiagoscamilo@gmail.com ( T. da S. Camelo )

Acadêmico do curso de Engenharia Civil da Universidade Federal do Pará. urbano em Belém - PA, medidos pela opinião dos usuários, esta pesquisa analisa a qualidade do sistema de transporte coletivo realizado por ônibus em um sistema não integrado. Por meio da aplicação de uma pesquisa de opinião com uma amostra dos usuários e, levantamento de critérios de qualidade do serviço, essa pesquisa analisou o grau de percepção de qualidade desse meio de transporte, tendo como referencial básico, parâmetros utilizados na biografia já publicada. Por meio da análise dos resultados determinou-se o nível do serviço ofertado pelas empresas operadoras do transporte coletivo em Belém. Fornecendo, assim, um diagnóstico a respeito da qualidade deste serviço que pode servir de subsídio na formulação de políticas públicas que visem melhorar o transporte público urbano em Belém - PA.

ABSTRACT: Based on the quality indicators of the urban public transportation system in Belém - PA, measured by the opinion of users, this research analyses the quality of public transport system of the bus modality, in a non-integrated model. Through the application of a opinion survey, with a sample of the users and the determination of service quality indicators, this research analyzed the level of user perception about the quality of the service provided by this typology of transport, taking as a reference for the development of this research, parameters used in the published biography. Through the results analysis, it was determined the service quality level offered by the public transport companies in Belém. Thus, the main contribution of this research is to provide a data base for public policy formulation allowances to improve urban public transport in Belém - PA.

RESUMO: Com base nos indicadores de qualidade do sistema de transporte coletivo 


\section{INTRODUÇÃO}

Desde os primórdios, transportar é um serviço que acompanha o homem, tendo crescido como atividade econômica, junto a serviços de comunicação e financeiros, a partir da revolução industrial.

Decorrente da revolução industrial, o transporte público apareceu quase simultaneamente em várias cidades. A produção antes feita nas casas dos trabalhadores passou a ser realizada em fabricas equipadas com maquinas e ferramentas especiais, gerando a necessidade dos operários a se deslocar diariamente ás fabricas.

Segundo Faria (1985) a primeira linha de bonde impulsionada por motor elétrico, efetivamente bem-sucedida, surgiu em 1888 nos Estados Unidos, na cidade de Richmond. O bonde em tração elétrica tinha menor custo e maior segurança comparado aos outros sistemas de transporte da época (sistema de tração por cabos).

O surgimento dos primeiros ônibus movidos a derivados de petróleo deu-se em aproximadamente 1890 , sendo utilizados em várias cidades da Alemanha, Inglaterra e França. Posteriormente a Europa os ônibus a gasolina começaram a circular nos Estados Unidos, na cidade de Nova York em 1905.

A partir de 1920, agora com ônibus movidos a óleo diesel, os ônibus passaram a substituir os bondes no transporte urbano devido a várias vantagens: menor custo, não utilizando cabos, trilhos e subestação de energia; flexibilidades nas rotas, pois o mesmo pode desviar de vias bloqueadas ou com problemas; maior confiabilidade, pois não paralisam com a interrupção do fornecimento de energia (FERRAZ, 1988).

Com o desenvolvimento das grandes cidades, a necessidade de políticas públicas de mobilidade urbana ganha papel de fundamental importância. Com o intuito de proporcionar a interligação entre várias regiões das cidades o transporte coletivo é importante na configuração dos deslocamentos urbanos, atuando como alternativa à redução de problemas como: impactos ambientais, acidentes de transito e congestionamentos.
Devido a intensa movimentação de pessoas e produtos no atual contexto das cidades, a escolha do modelo de transporte analisa fatores como: qualidade do serviço, viabilidade econômica e geográfica, condições de transito, disponibilidade do modelo e preferência (WAISMAN, 1983). No caso de Belém, cidade foco do estudo, o modelo de transporte público urbano atual é o sistema de ônibus não integrados.

A evolução urbana está condicionada a um esquema de circulação de acordo com as tecnologias de transporte disponíveis para possibilitar a inter-relação entre as atividades urbanas - residência, trabalho, estudo, lazer, etc. Neste contexto o transporte público de passageiros possui grande relevância com a função de integrar espaços urbanos. Com isso, o mesmo passa a ter tal importância de serviços como: fornecimento de luz e água, saneamento básico e etc.

Segundo o exposto acima o objetivo deste artigo é analisar, através de um estudo de caso, a percepção qualitativa dos usuários do transporte público da cidade de Belém-PA.

\section{REVISÃO BIBLIOGRÁFICA}

\subsection{QUALIDADE NO TRANSPORTE PÚBLICO COLETIVO}

Todos os seguimentos da sociedade beneficiam-se da existência de um transporte público de qualidade (JURAN, 1990). Segundo Lima Jr. (1995) a qualidade está associada a valorização da visão do cliente, gestão dos processos e motivação das pessoas para melhoria continua e para a busca da excelência. O mesmo também destaca que os investimentos no desenvolvimento da área de transporte tem enfoque no processo de produção dos serviços, com pouca ênfase à satisfação dos usuários.

Um objetivo fundamental nas políticas de mobilidade urbana é a transferência de viagens dos automóveis para os ônibus. Vasconcellos (1996) aponta como solução mais viável a oferta de serviços especiais de ônibus de qualidade, com veículos sofisticados e confortáveis, que atravessem bairros de classe média e realizem poucas paradas. 
Comparando o espaço viário consumido por um automóvel pelo espaço consumido por um ônibus. Um automóvel ocupa cerca de $7 \mathrm{~m}^{2}$ de espaço viário e transporta em média 1,5 passageiros, com isso cada passageiro ocupa aproximadamente $5 \mathrm{~m}^{2}$ de espaço viário. Já um ônibus que ocupa cerca de $30 \mathrm{~m}^{2}$ de via e transporta em média 60 passageiros, com isso cada passageiro ocupa $0,5 \mathrm{~m}^{2}$ de via. Mostrando que automóveis ocupam aproximadamente dez vezes mais espaço viário que ônibus para levar o mesmo número de pessoas (SILVA e FERRAZ, 1991).

A viagem por transporte público urbano (ônibus) compõe-se das seguintes etapas: percurso a pé do ponto de origem ao local de embarque, espera pelo ônibus, viagem dentro do coletivo e percurso do ponto de descida até o destino. Algumas vezes sendo necessário a transferência entre coletivos para se chegar no destino desejado (VASCONCELOS, 1996).

Segundo Tironi (1991), a qualidade de um serviço pode ser avaliada por meio de indicadores de produtividade e qualidade. Esses indicadores devem ser de simples formulação e de fácil entendimento por todos os envolvidos no processo.

Ferraz e Torres (2004) apresentam 12 critérios para analisar a qualidade do sistema de transporte público urbano resumidos na Figura 1.

\subsection{CARACTERÍSTICAS DO SISTEMA DE TRANSPORTE PÚBLICO COLETIVO DE BELÉM-PA}

A lei Orgânica do Município de Belém (SEMAJ, 1990) em seu capitulo $V$, nas disposições de transporte e Art. 146 disserta que as necessidades sociais dos cidadãos terão prioridades.

“Art. 146, O sistema viário e os meios de transporte no Município, atenderão, prioritariamente, às necessidades sociais do cidadão, como as de deslocamento da pessoa humana no exercício da garantia constitucional da liberdade de locomoção e, no seu planejamento, organização, implantação, gerenciamento, operação, prestação e fiscalização".

O regulamento do serviço de transporte coletivo por ônibus do município de Belém define que compete à Companhia de Transportes do Município de Belém - CTBel, criada pela Lei Municipal n. ${ }^{\circ} 7.475 / 1989$, hoje renomeada para Superintendência Executiva de Mobilidade Urbana de Belém - SEMOB, que é responsável pelo planejamento, a operação, o ordenamento, o controle e a fiscalização do Serviço Regular de Transporte Coletivo por Ônibus do Município de Belém, nos termos do Art. 147 da Lei Orgânica do Município de Belém.

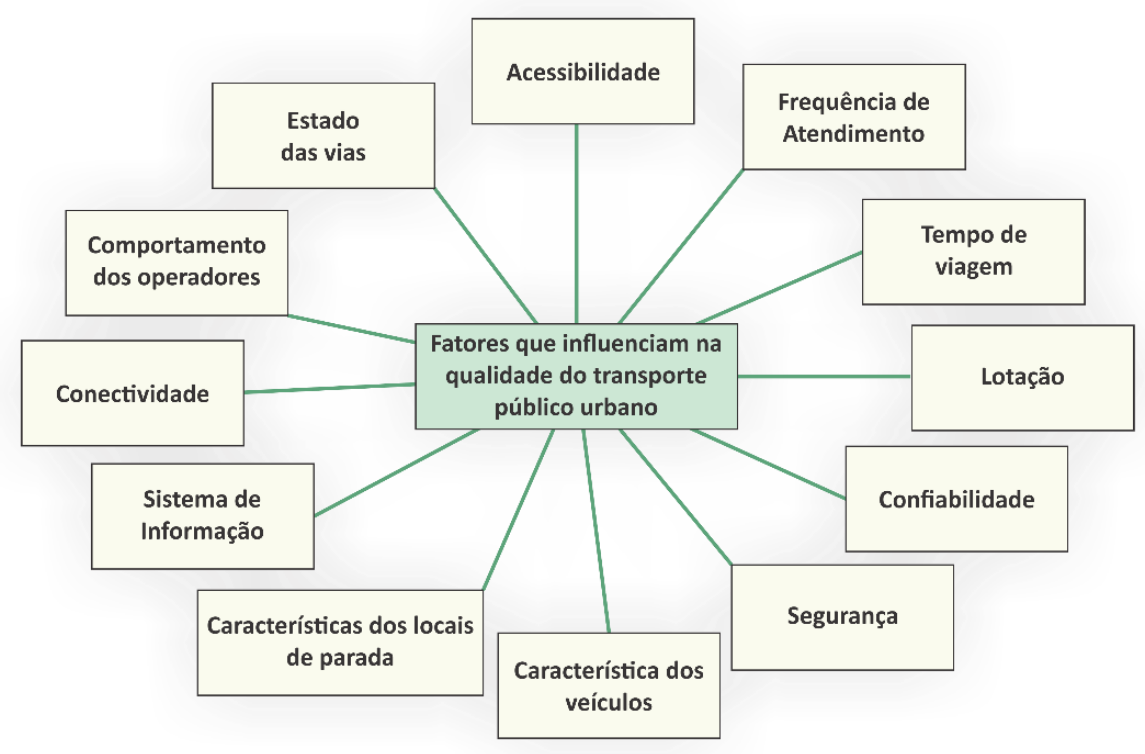

FIGURA 1: Indicadores de qualidade.

FONTE: Ferraz e Torres (2004). 
O sistema de transporte Coletivo de Belém obedece ao regulamento do serviço de transporte coletivo por ônibus do município de Belém e tem como órgão gerenciador desse regulamento a SEMOB, sendo de responsabilidade de esta determinar, mediante expedição de Ordem de Serviço, as características operacionais de cada linha, especialmente:

"I - os pontos inicial e terminal;

II - os itinerários detalhados de ida e volta;

III - os pontos seletivos de parada de ônibus integrante dos itinerários;

IV - as frequências de viagens, por faixa horária, diferenciadas para dias úteis, sábado, domingo, feriados e outros;

$V$ - o número de veículos exigidos para operação diferenciado para dias úteis, sábado, domingo, feriados e outros;

VI - o tempo de permanência nos terminais; $e$ VII - o tipo de equipamento exigido na operação.". A seleção de empresas prestadoras do serviço público de transporte será feita mediante licitação nos termos da legislação. A exploração do serviço de transporte será formalizada mediante contrato de concessão ou permissão.

Depois de formalizado contrato, serão obrigações das Empresas Operadoras:

I - cumprir os preceitos constitucionais e legais, bem como este Regulamento $e$ outros atos administrativos expedidos pela SEMOB;

II - manter seguro de responsabilidade civil para passageiros e terceiros;

III - manter em ordem os seus registros na SEMOB; IV - informar à SEMOB as alterações de localização das instalações da empresa;

$V$ - permitir o acesso dos fiscais credenciados da $S E M O B$ aos veículos e instalações, bem como daqueles formalmente designados para examinar a respectiva escrituração e proceder a tomada de suas contas;

VI - possuir veículos de reserva em número não inferior a 10\% (dez por cento) do total de veículos de sua frota;

VII - estruturar seus planos de contas de acordo com as instruções da SEMOB (2008);

VIII - informar a SEMOB dentro das condições e dos prazos estabelecidos tudo que Ihes for solicitado;
IX - cumprir as especificações e características de operação do serviço permitido;

$X$ - manter sempre atualizados e em perfeitas condições, os sistemas de controle de passageiros transportados, de quilometragem percorrida e de viagens realizadas, segundo as normas da SEMOB; $X I$ - preservar a inviolabilidade das roletas, comunicando a SEMOB quaisquer acidentes ocorridos com as mesmas e providenciando, no prazo de 48 (quarenta e oito) horas, nova selagem junto à vistoria;

XII - dar condições dignas e seguras de trabalho ao seu pessoal de operação;

XIII - garantir a segurança e o conforto dos passageiros;

XIV - cobrar o preço exato da tarifa em vigor;

$X V$ - submeter seus veículos à vistoria, colocando-

os em operação em perfeito estado de funcionamento $e \mathrm{em}$ plenas condições de segurança;

$X V I$ - não permitir a circulação dos ônibus sem a documentação obrigatória do veículo, do motorista e do cobrador;

XVII - apresentar seus veículos para início de operação em adequado estado de conservação e limpeza;

XVIII - não utilizar na limpeza dos veículos substâncias que coloquem em risco a segurança dos passageiros;

$X I X$ - recolher à SEMOB, nas condições e prazos fixados, todos os valores que a ela forem devidos; $X X$ - permitir, facilitar e auxiliar a SEMOB em levantamento de informações necessárias ao funcionamento do sistema;

$X X I$ - não alterar as características da prestação do serviço;

XXII - providenciar meios de transportes aos passageiros, com vistas a complementação da viagem, no caso da sua interrupção;

XXIII - manter programas permanentes de treinamento para o seu pessoal, particularmente para os que desempenham funções relacionadas com a segurança do transporte e o trato com o público.".

\section{METODOLOGIA}

A pesquisa foi realizada na cidade de 
Belém-PA, onde o transporte público urbano utilizado é o modo ônibus em um sistema não integrado. O objeto da pesquisa foi uma das linhas de maior fluxo de passageiros, segundo informações da SEMOB (Superintendência Executiva de Mobilidade Urbana de Belém). Para a coleta de dados foi elaborado um questionário com base nos indicadores de Ferraz e Torres (2004), com o objetivo de obter a percepção qualitativa dos usuários desta linha.

Os pesquisadores se deslocaram junto a SEMOB a fim de coletar dados da linha em questão, como número de passageiros por dia, extensão dos itinerários, número de veículos e intervalos as viagens. Por amostragem foi definido a aplicação aleatória de 1500 usuários do transporte público em Belém, sendo desconsiderados moradores dos outros municípios da região metropolitana, sendo 982 do sexo feminino e 518 do sexo masculino, todos maiores de 18 anos.

Barbetta (2002) define a Equação 1 para a primeira aproximação do tamanho da amostra:

$$
n_{0}=\frac{1}{E_{0}^{2}}
$$

Em que:

$n_{0}=$ Primeira aproximação do tamanho da amostra;

$E_{0}=$ Erro amostral tolerável.

Para populações pequenas, Barbetta (2002) define o tamanho da amostra de acordo com a Equação 2:

$$
n=\frac{N * n_{0}}{N+n_{0}}
$$

Em que:

$n$ = Segunda aproximação do tamanho da amostra;

$n_{0}=$ Tamanho da amostra corrigido;

$N=$ Tamanho da população que utiliza o transporte publico diariamente.

Para uma população de aproximadamente 366.136 usuários do transporte coletivo por dia, define-se o tamanho da amostra corrigida, segundo dados da SEMOB (2010). Para trabalhar-se com números mais precisos, foi tomada uma amostra de 1.500 usuários para conseguir-se significância estatística, e resultando um erro de $2,60 \%$.

Com objetivo de captar a opinião do usuário acerca da qualidade do STP da cidade de Belém, foi aplicado um questionário para o qual os usuários deveriam responder com as seguintes notas: 5 (Excelente); 4 (Bom); 3 (Regular); 2 (Ruim) e 1 (Muito Ruim). No questionário constavam os 12 critérios, sendo estes e seus quesitos de avaliação:

I. Acessibilidade: Distância percorrida da residência até a parada e do ponto de descida do ônibus até o destino.

II. Sistema de Informação: Informações sobre linhas, horários, destinos, trajetos, etc. Nas paradas e nos veículos.

III. Frequência de Atendimento: Tempo de espera entre os ônibus da mesma linha.

IV. Lotação: Índice de lotação dos ônibus.

V. Tempo de Viagem: Tempo de duração da viagem.

VI. Confiabilidade: Os ônibus cumprem os horários de passagem nas paradas e os intervalos.

VII. Característica dos Veículos: Estado de conservação, conforto, depreciação e limpeza.

VIII. Características das Paradas: Estado de conservação, conforto e acessibilidade da parada.

IX. Comportamento dos Operadores: Desempenho dos motoristas e cobradores ao atenderem os usuários e exercerem suas funções.

X. Segurança: Acidentes e assaltos nos veículos.

XI. Estado das Vias: Condições e conservação das vias onde os veículos trafegam.

XII. Tarifa: Valor da passagem em relação à qualidade do serviço oferecido pela empresa.

Apenas uma modificação foi feita dos critérios estabelecidos por Ferraz e Torres (2004), onde o original "conectividade" foi substituído por "tarifa", sabendo da ausência de um terminal de integração na cidade de Belém, logo, não há conectividade.

\section{ANÁLISE DOS RESULTADOS DA PESQUISA}

\subsection{ACESSIBILIDADE}


Durante a aplicação do questionário, foi possível observar maior satisfação (avaliando como "excelente" ou "bom") dos usuários que transitam principalmente pela área central de Belém, onde a densidade de paradas é maior e a infraestrutura urbana é melhor. Por outro lado, foi possível observar maior insatisfação (avaliando como "ruim" ou "muito ruim") dos usuários residentes das áreas mais periféricas da capital, onde o índice de paradas é inferior e as condições de conservação das vias de acesso aos pontos, normalmente, deixa a desejar. O grau de satisfação dos usuários a respeito da acessibilidade ao transporte público é mostrado na Figura 2.

\subsection{SISTEMA DE INFORMAÇÃO}

Um bom sistema de informação, que sane todas as possíveis dúvidas do usuário, é inestimável para a compreensão de um sistema de transporte urbano, ainda mais para um sistema tão complexo como o de uma capital. O sistema de informação deve beneficiar não somente o usuário "padrão" (considerando o usuário "padrão", aquele que utiliza diariamente o sistema de transporte público e, é morador da cidade de Belém), mas, também, o usuário eventual (seja um morador de Belém que não utilize frequentemente o transporte público da cidade, ou um turista, que não é familiarizado com o funcionamento do sistema de transporte de Belém, e que não possui familiaridade coma as linhas, ruas, etc.).

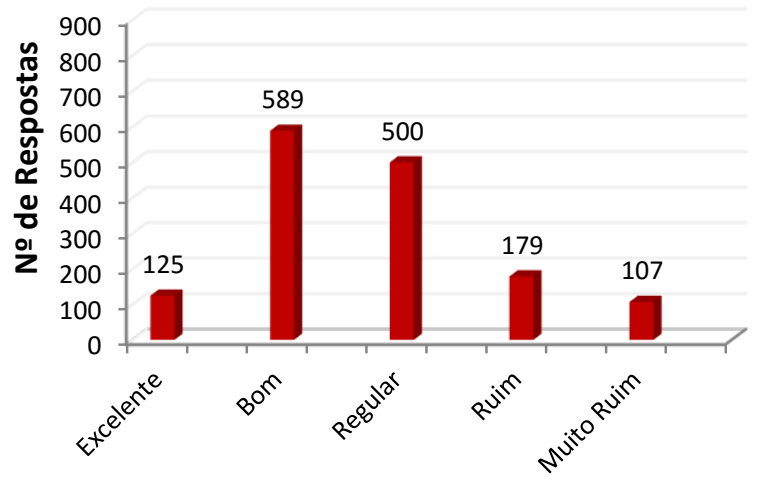

FIGURA 2: Gráfico de análise de percepção sobre o aspecto de Acessibilidade.
Quando questionados sobre o Sistema de Informação da cidade de Belém, os usuários demonstraram grande insatisfação. Observando o gráfico da Figura 3, mais da metade dos entrevistados avaliaram o sistema como "ruim" ou "muito ruim", o que indica uma grande necessidade de melhoria, na visão do usuário.

\subsection{FREQUENCIA DE ATENDIMENTO}

A frequência de atendimento consiste no intervalo de tempo entre a passagem de coletivos de uma mesma linha, no mesmo sentido. Intervalos estes que quando não respeitados pelas companhias operadoras do transporte público, acarretam o aumento do volume de usuários aguardando em paradas e o aumento do índice de lotação dos veículos, considerando que a irregularidade dos horários de passagem resultaria na má distribuição dos usuários ao longo da frota (alguns veículos estariam lotados, enquanto outros estariam vazios).

Fazendo a análise do gráfico da Figura 4, é possível observar que aproximadamente $62 \%$ dos usuários entrevistados avaliaram negativamente (como "ruim" ou "muito ruim") a Frequência de Atendimento em Belém. Verifica-se então a necessidade de melhoria desse indicativo. Seja intensificando a fiscalização para verificar se as empresas operadoras estão cumprindo o ordenado, ou seja, fazendo uma reciclagem dos estudos de demanda da população, considerando que os mesmos possam estar defasados.

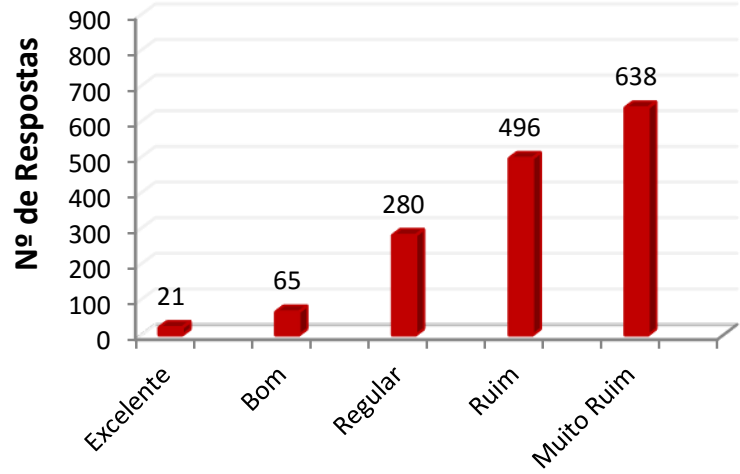

FIGURA 3: Gráfico de análise de percepção sobre o Sistema de Informação. 


\subsection{LOTAÇÃO}

A lotação de um veículo corresponde a sua capacidade máxima de transporte de passageiros, sentados e em pé. Este número pode variar de acordo com o modelo do veículo (microônibus, veículo de duas portas, veículo de três portas, veículo articulado, etc.) e, também, de acordo com leis municipais ou estaduais, que podem reduzir a capacidade de transporte de passageiros por medidas de segurança, ou até mesmo para o maior conforto do usuário, mesmo que o veículo tenha sido fabricado para o transporte de uma quantidade maior.

Analisando o gráfico da Figura 5, é possível observar uma avaliação bastante negativa na visão do usuário. Aproximadamente $78 \%$ dos entrevistados avaliaram como "ruim" ou "muito ruim" o aspecto lotação dos ônibus da cidade de Belém. Isso indica uma necessidade de reformulação, seja na frota (aumento da quantidade de veículos, para que o volume de usuários seja diluído), ou na frequência de atendimento da população (diminuir o tempo de passagem entre um veículo e outro nas paradas, principalmente nos horários de pico).

\subsection{TEMPO DE VIAGEM}

É possível observar que o critério Tempo de Viagem sofre a influência de vários outros aspectos de qualidade em todas as etapas do seu processo. As etapas 1 e 6 dependem diretamente da Acessibilidade.

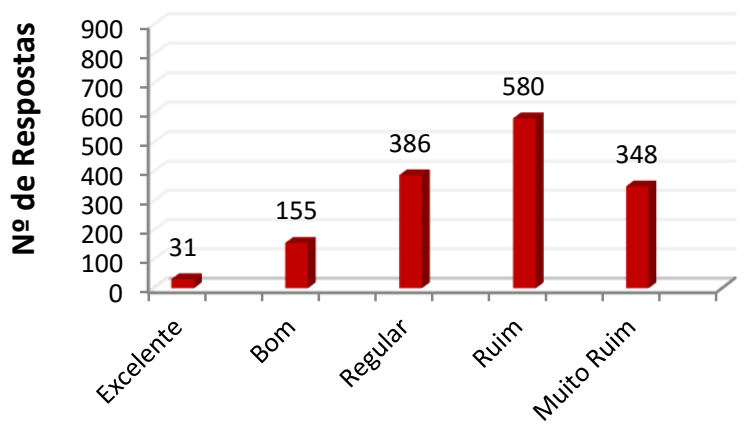

FIGURA 4: Gráfico de análise de percepção sobre a Frequência de atendimento.
FONTE: Próprio autor.
A etapa 2 é diretamente influenciada pela Frequência de Atendimento e Confiabilidade do sistema de transporte. As etapas 3 e 5 podem ter a interferência da Lotação. Por fim, a etapa 4 é influenciada pela Característica dos Veículos e Estados das Vias e, também, pela intensidade do trânsito no momento do percurso.

Aproximadamente $30 \%$ dos entrevistados avaliaram este indicador como "regular", sendo que, $55 \%$ dos entrevistados demonstraram insatisfação com o quesito em questão (avaliando como "ruim" ou "muito ruim"), como é possível ver na Figura 6.

\subsection{CONFIABILIDADE}

A Confiabilidade consiste no grau de confiança que o usuário pode depositar no sistema de transporte urbano de sua cidade. Sempre que o usuário necessita do sistema de transporte, ele possui expectativas que ele espera que sejam atendidas. É esperado que o veículo passe no horário correto no local de parada; é esperado que a viagem ocorra do tempo correto do trajeto, sem maiores problemas, ainda que respeitando algum tempo de tolerância.

Avaliando o gráfico da Figura 7, é possível observar que aproximadamente $33 \%$ dos entrevistados estão satisfeitos com o serviço, o qualificando como "regular". Por outro lado, em torno de $50 \%$ estão insatisfeitos, avaliando o sistema como "ruim" ou "muito ruim", e somente $17 \%$ confiam no sistema de transporte público de Belém, considerando como "bom" ou "excelente".

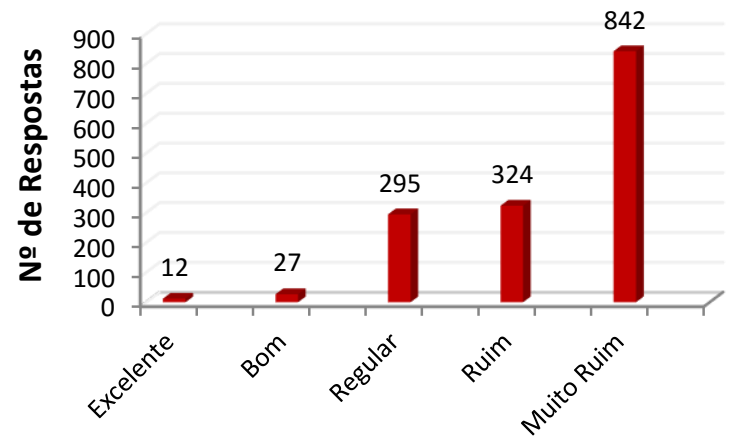

FIGURA 5: Gráfico de análise de percepção sobre o aspecto lotação. 


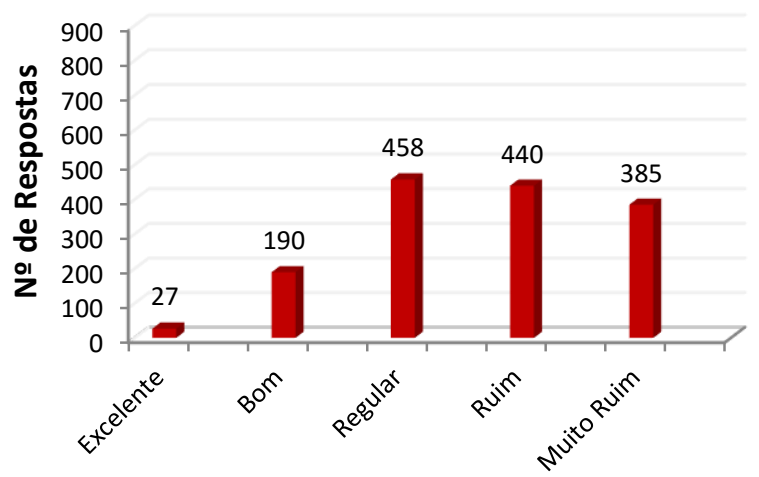

FIGURA 6: Gráfico de análise de percepção sobre o tempo de viagem. FONTE: Próprio autor.

\subsection{CARACTERÍSTICAS DOS VEÍCULOS}

Vários são os aspectos observados quanto a conservação e estrutura dos veículos: pintura e limpeza; sinalização (principalmente a respeito da linha e seu trajeto); assentos (anatomia e conforto, existência ou ausência de estofamento); iluminação; ventilação e umidade; existência de cordões e/ou botões de solicitação de parada (diferentes modalidades podem ser utilizadas, de acordo com a estatura do usuário); largura dos corredores (quanto mais largos, maior o conforto e facilidade movimentação dentro do veículo, principalmente nos horários de pico); quantidade de barras de apoio (que auxiliam na movimentação no interior do veículo, principalmente quando em movimento, principalmente a mulheres, crianças e idosos); quantidade e largura das portas (facilitam e aceleram os procedimentos de embarque e desembarque, principalmente nos horários de pico); manutenção mecânica dos veículos (ruídos e barulhos provenientes de peças soltas ou desgastadas).

Quando questionados acerca das características dos veículos do transporte público da cidade de Belém, a maioria dos usuários demonstrou insatisfação. Aproximadamente 60\% dos entrevistados qualificaram os veículos como "ruins" ou "muito ruins". Enquanto, 31\% consideraram "regular" e, somente $9 \%$ se demonstraram satisfeitos e avaliaram os veículos como "bons" ou "excelentes" (Figura 8).

0 grande índice de insatisfação explicita uma urgente necessidade de modificação dos padrões utilizados atualmente pelas empresas que

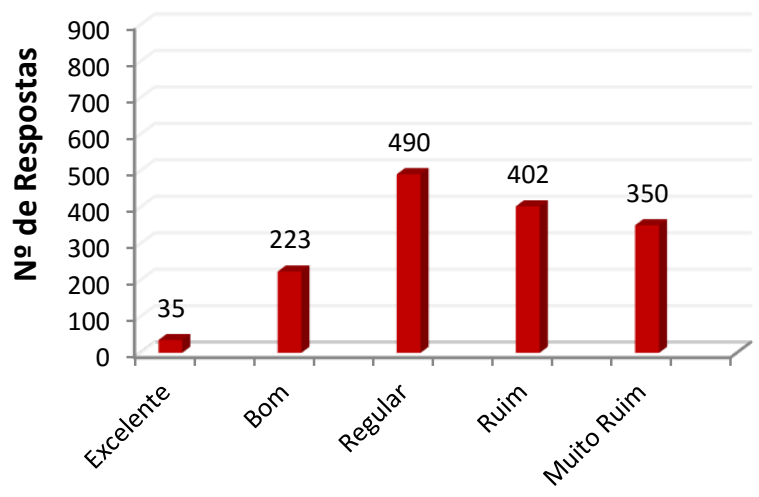

FIGURA 7: Gráfico de análise de percepção sobre o aspecto confiabilidade. FONTE: Próprio autor.

têm a concessão para prestar esse serviço para a população. Seja fazendo uma renovação da frota (caso a idade média da em utilização seja elevada), ou seja, fazendo algumas adequações dos veículos, para a maior satisfação do seu público alvo.

\subsection{CARACTERÍSTICAS DAS PARADAS (PONTOS DE ÔNIBUS)}

O local de parada é uma das primeiras etapas do processo de quem utiliza o sistema de transporte urbano e, também, onde o usuário "desperdiça" parte do seu tempo dedicado à utilização do sistema.

De acordo com a SEMOB (2012), na cidade de Belém existem 1.425 pontos de parada. Entretanto, destes, somente 486 são equipados com mobiliário urbano, ou seja, possuem abrigos e coberturas, e somente alguns desses possuem assentos. Desta forma, 939 pontos são apenas indicados por placas, mas não oferecem qualquer tipo de estrutura básica para a segurança e proteção do usuário, que fica à mercê dos agentes climáticos e meteorológicos.

Analisando o gráfico da Figura 9, que expõe a opinião do usuário acerca das características das paradas na cidade de Belém, verifica-se que $2 \%$ avaliou este critério como "excelente" ou "bom" e 20\% como regular. Enquanto 78\%, grande maioria, julgou o mesmo como "ruim" ou "muito ruim". Dados estes que quando avaliados em conjunto com os dados de números de paradas sem mobiliário urbano na cidade de Belém, faz tornar compreensível a insatisfação da população. 


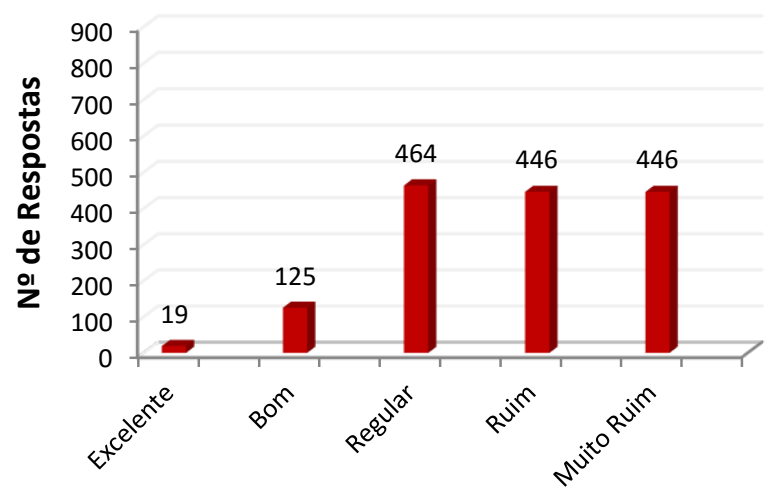

FIGURA 8: Gráfico de análise de percepção sobre as características dos veículos. FONTE: Próprio autor.

\subsection{COMPORTAMENTO DOS OPERADORES}

Considera-se neste critério de qualidade os "Operadores" como os motoristas e cobradores dos ônibus, sendo estes os funcionários das empresas prestadoras de serviço de transporte, que mais têm contato direto com o usuário. Assim, sendo o fator humano o único a ser avaliado neste quesito.

Analisando o gráfico da Figura 10, observa-se que $46 \%$ dos entrevistados avaliaram este critério como "regular", o que aponta um desempenho medíocre. Enquanto que 13\% julgaram como "excelente" ou "bom" e $41 \%$ como "ruim" ou "muito ruim". Estes resultados apontam para a necessidade de melhoria deste critério, cuja consequência do mau atendimento, talvez tenha origem na sobrecarga de trabalho, na máremuneração ou na falta de treinamento dos operadores.

\subsection{SEGURANÇA}

Considerando-se $\mathrm{o}$ aspecto segurança, considerou-se a avaliação de todos os tipos de sinistros que possam atentar contra a integridade física de todo e qualquer componente do sistema de transporte público. Tanto os fatores humanos (usuários, operadores e terceiros), como as estruturas físicas do sistema (locais de parada, terminais, estações, veículos, etc.).

Verifica-se na Figura 11 que o resultado se reflete na opinião do usuário. Onde somente $11 \%$ avaliaram como "excelente" ou "bom", 28\% consideraram o critério como "regular" e, a maioria

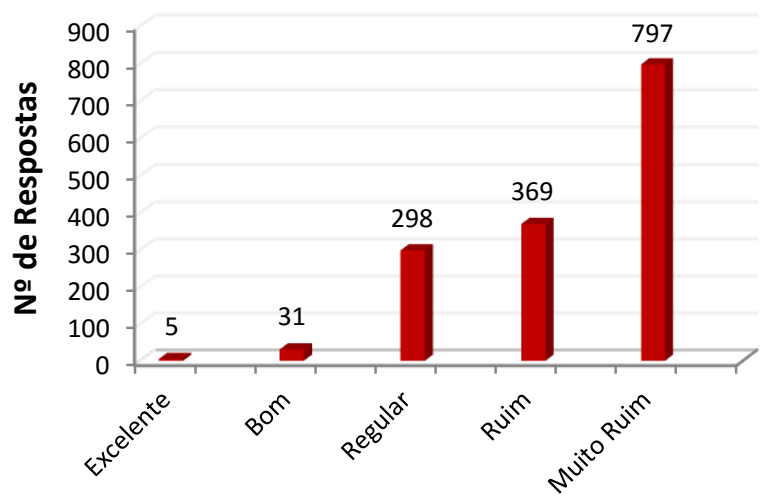

FIGURA 9: Gráfico de análise de percepção sobre as características das paradas.

FONTE: Próprio autor.

de $61 \%$ julgou as atuais circunstâncias como "ruim" ou "muito ruim".

\subsection{ESTADO DAS VIAS}

O estado de conservação das vias de rolamento é fundamental para o bom funcionamento do trânsito em qualquer cidade. Caso a via não se encontre nas situações ideais de tráfego, vários outros critérios de qualidade serão afetados. A frequência de atendimento não poderá ser mantida, já que os veículos não poderão realizar as viagens na velocidade média planejada.

Analisando o gráfico da Figura 12, é possível que boa parte dos entrevistados encontra-se conformado com o critério de qualidade do estado das vias, tendo em vista que $43 \%$ o qualificaram como "regular". Enquanto $22 \%$ caracterizaram como "excelente" ou "bom" e 35\% avaliaram como "ruim" ou "muito ruim". Ainda, assim, nota-se a necessidade de melhoria neste aspecto.

\subsection{TARIFA}

Os usuários foram questionados se achavam justo o valor da tarifa da cidade de Belém, em relação ao serviço prestado pelas empresas que tem concessão para tal. Conforme a Figura 13, aproximadamente $33 \%$ dos entrevistados, se demonstraram satisfeitos com valor da tarifa avaliando o critério como "regular". Enquanto 15\% avaliaram o valor como "excelente" ou "bom". Por fim, a maioria, 52\%, julgou a tarifa cobrada não compatível com o serviço prestado, considerandoa "ruim" ou "muito ruim". 


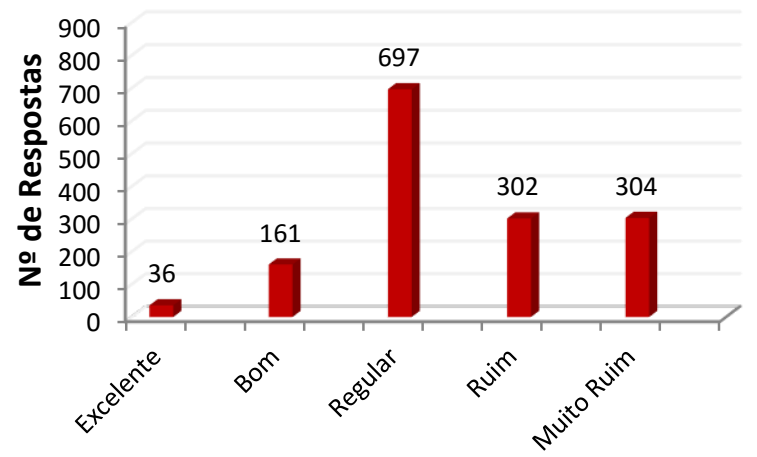

FIGURA 10: Gráfico de análise de percepção sobre os operadores (cobrador e motorista). FONTE: Próprio autor.

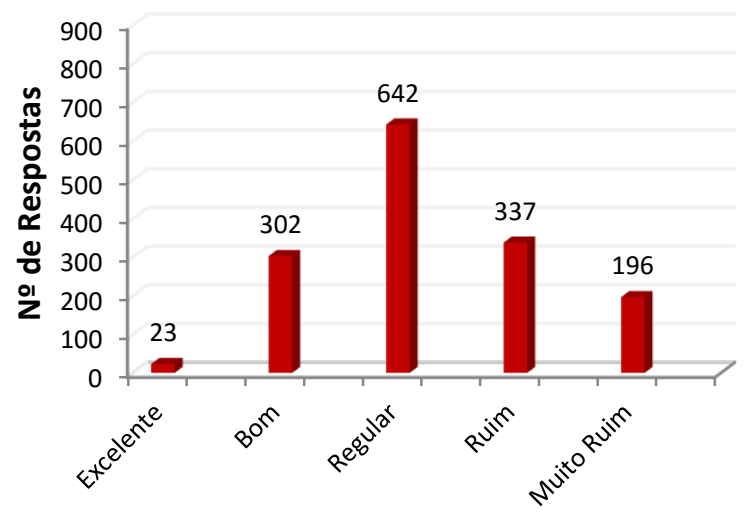

FIGURA 12: Gráfico de análise de percepção sobre o estado das vias de rolamento.

FONTE: Próprio autor.

\section{CONSIDERAÇÕES FINAIS}

Este trabalho foi realizado com o intuito de gerar uma imagem ampla e clara da real situação do STP da cidade de Belém - PA, com base na avaliação dos critérios de qualidade propostos por Ferraz e Torres (2004), na visão do usuário. Os resultados obtidos apontam os pontos satisfatórios e os pontos críticos do sistema analisado e, onde as melhorias são necessárias e quais suas causas e possíveis soluções.

A acessibilidade foi o critério de qualidade com a melhor avaliação dentre os pesquisados. Este aspecto foi avaliado por $33 \%$ dos usuários entrevistados como "regular", por $48 \%$ como "bom" ou "excelente" e somente 19\% como "ruim" ou "muito ruim". Isto indica que, em sua maioria, os usuários estão satisfeitos com as infraestruturas de acesso aos locais de parada. Entretanto, isto não significa que não há espaço para melhorias.

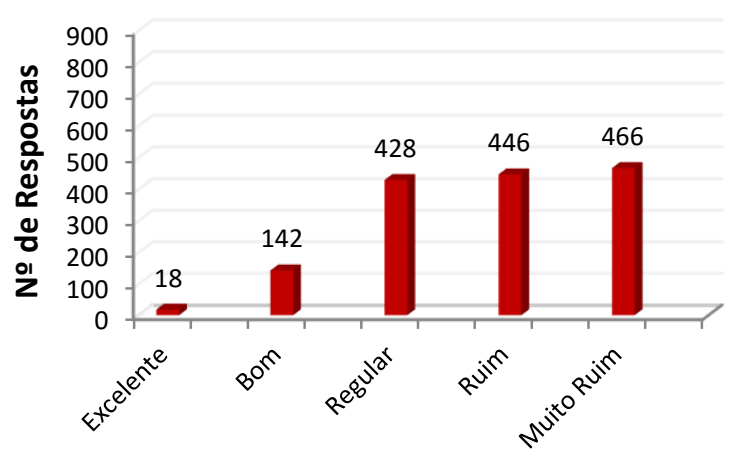

FIGURA 11: Gráfico de análise de percepção sobre a segurança.

FONTE: Próprio autor.

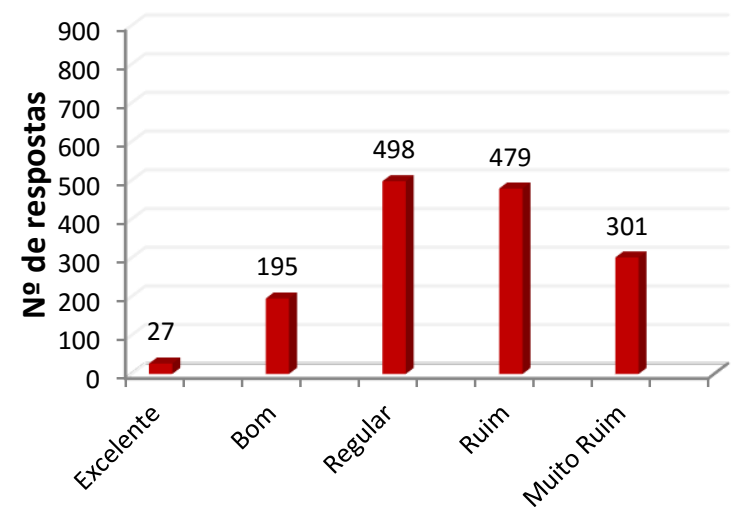

FIGURA 13: Gráfico de análise de percepção sobre a tarifa.

FONTE: Próprio autor.

Pôde-se observar um pequeno grau de satisfação com os serviços prestados relacionados ao comportamento dos operadores e estado das vias de condução. Nesses aspectos as opiniões se apresentaram predominantemente como "regular". No primeiro $46 \%$ avaliaram como "regular", 13\% como "bom" ou excelente" e 41\% como "ruim" ou "muito ruim". Enquanto, no segundo, $43 \%$ julgaram como "regular", $22 \%$ como "bom" ou "excelente", 22\% como "ruim" e 13\% como "muito ruim". Alguns entrevistados se manifestaram apontando a necessidade de melhor treinamento aos operadores e de melhoria na estrutura das vias, para melhor condição de rolamento.

O critério de qualidade com pior avaliação foi a lotação, onde a expressiva quantidade de $56 \%$ dos entrevistados avaliaram o quesito como "muito ruim", 22\% como "ruim", 19\% como "regular" e somente $3 \%$ como "bom" ou "excelente". Como já debatido, a lotação influencia muito na percepção 
de conforto e segurança do usuário, tendo em vista que em situações de lotação máxima, o usuário dificilmente viaja sentado e fica mais suscetível a furtos, coações, etc. Cabe aos órgãos controladores, modificação ou ajustamento das leis que regulam o índice de lotação máxima dos veículos, a fim de propiciar o aumento de frota, a atualização dos estudos de demanda, entre outras medidas que possam gerar melhorias.

Em segundo, encontra-se Características das Paradas, onde a $53 \%$ dos entrevistados julgaram como um aspecto "muito ruim", 25\% como "ruim", 20\% como "regular" e somente $2 \%$ avaliaram como "bom" ou "excelente". Avaliando estes resultados em conjunto com a estatística acerca dos pontos de parada em Belém, torna-se nítido o motivo de insatisfação do usuário. Em uma capital onde somente $34 \%$ dos pontos de parada possuem qualquer tipo de proteção ao usuário (contra intempéries e agentes climáticos), os investimentos para a criação de novas estruturas de apoio deveriam ser tratados em caráter de urgência.

Os critérios de qualidade relacionados com as características dos veículos e a segurança receberam avaliações muito similares. Em torno de $60 \%$ dos entrevistados opinaram como "ruim" ou "muito ruim", enquanto aproximadamente $30 \%$ julgaram como "regular" e somente $10 \%$ como "bom" ou "excelente". Logo, percebe-se a insatisfação para com a segurança oferecida dentro e fora dos veículos e o desconforto das estruturas veiculares.

Os demais critérios avaliados foram avaliados de forma similar, predominantemente insatisfatório. Em que ao menos $50 \%$ dos entrevistados responderam considerar os critérios como "ruim" ou "muito ruim", em média de $20 \%$ a $30 \%$ consideram como "regular" e somente a minoria os avaliou de forma satisfatória, como "bom" ou "excelente". Nota-se então, a urgente necessidade de reformulações e modificações para que hajam melhorias nos mais variados aspectos do STP da cidade de Belém.

Este trabalho contribuiu com o levantamento de dados a respeito da percepção do usuário a respeito da qualidade do transporte público de Belém do Pará. Assim, a base de dados levantada por meio desta pesquisa, pode contribuir para um melhor entendimento do sistema de transporte público da cidade, apontando pontos falhos que necessitam melhorias e possibilitando a adoção de ações públicas para uma melhor gestão do transporte urbano de Belém.

\section{REFERÊNCIAS BIBLIOGRAFIAS}

BARBETTA, Pedro Alberto. Estatísticas aplicadas ás ciências sociais. 5. Ed. Florianópolis: Ed. Da UFSC, 2002, 340p.

CÂMARA MUNICIPAL DE BELÉM. Lei Municipal № 7.475. Cria a Companhia de Transportes do Município de Belém (CTBEL), autoriza medidas transitórias referentes ao transporte de passageiros e dá outras providências. 1989.

FARIA, C.A. Percepção do usuário com relação ás características do nível de serviço do transporte coletivo urbano por ônibus. São Carlos. Dissertação (Mestrado) - Escola de Engenharia de São Carlos - USP. 1985.

FERRAZ, Antônio Clóvis Pinto e TORRES, Isaque Guilherme Espinosa. Transporte público urbano. São Paulo, Rima, 2004, 410p.

FERRAZ, Antônio Clóvis Pinto. A qualidade do serviço de transporte coletivo em cidades médias sob a ótica dos usuários. In: ENCONTRO NACIONAL DA ANPET, 2, São Paulo, 1988.

JURAN, J.M. Juran na liderança pela qualidade. São Paulo. Pioneira. 1990, 386p.

LIMA JR., O.F. Qualidade em serviço de transporte: conceituação e procedimentos para diagnóstico. São Paulo, Tese (Doutorado) - Escola Politécnica, Universidade de São Paulo. 1995, 215p.

SEMAJ - Secretaria Municipal de Assuntos Jurídicos. Lei Orgânica de Belém. 1990.

SEMOB -Superintendência Executiva de Mobilidade Urbana de Belém. Regulamento do serviço de transporte coletivo por ônibus do município de Belém. Belém. 2012.

SEMOB -Superintendência Executiva de Mobilidade Urbana de Belém. Média mensal de usuários de ônibus do município de Belém. Belém. 2008.

SEMOB -Superintendência Executiva de Mobilidade Urbana de Belém. Relatórios das frotas de ônibus. Belém. 2010.

SILVA, Antônio Nelson Rodrigues da; FERRAZ, Antônio Clóvis Pinto. Transporte público urbano: operação e administração. Notas de aula. São Carlos: Escola de Engenharia de São Carlos - EESC - USP, 1991. 
TIRONI, L. F.; SILVA, L. C. E.; VIANA, L. M.; MEDICI, A. C. Critérios para a geração de indicadores de qualidade e produtividade no serviço público. IPEA - Textos para discursão interna. Brasília, 1991.

VASCONCELLOS, Eduardo Alcântara. Transporte urbano nos países em desenvolvimento: Reflexões e propostas. 1a ed. São Paulo: Editoras Unidas, 1996.

VASCONCELLOS, E. A. Transporte urbano nos países em desenvolvimento: Reflexões e propostas. São Paulo: Annablume, 2000, 282p.

WAISMAN, J. Avaliação do desempenho de sistema de ônibus, em cidades de porte médio, em função de sua produtividade, eficiência operacional e qualidade dos serviços. São Carlos, Tese (doutorado) - Escola de Engenharia de São Carlos - USP. 1983. 